\title{
The Prevalence of Stress \& Anxiety Among Patients Having Habit of Cheek Biting
}

\author{
Nabeel Naeem Baig ${ }^{1}$ \\ BDS, MPH \\ Khadijah Abid ${ }^{2}$ \\ MSc \\ Rabeya Fatima ${ }^{3}$ \\ BDS \\ Syeda Batool Ahsan ${ }^{4}$ \\ MBBS
}

OBJECTIVE: To determine the prevalence of stress and anxiety among patients with cheek biting visiting dental clinic for routine checkups.

STUDY DESIGN: Cross-sectional study

PLACE AND DURATION OF STUDY: Ameen medical and dental center, Karachi from July 2016 to Feb 2018. METHODOLOGY: Total of 101 patients were included in the study by using non-probability consecutive sampling technique after taking written informed consent from the participants. Patients coming to OPD for routine dental check up with complain of pain and burning in oral cavity were enrolled in the study. The data was analyzed by using Stata version 23.

RESULTS: Total 101 patients were enrolled in the study, stress was observed in 37(36.6\%) \& anxiety was observed in $34(33.7 \%)$. In univariate analysis, stress \& anxiety showed significant relation with history of psychiatric illness in family and family history of DM ( $\leq 0.05)$.

CONCLUSION: We found stress and anxiety were prevalent among patients with habit of cheek-biting. History of psychiatric illness and diabetes mellitus played significant role and showed statistical relation with stress and anxiety $(\mathrm{p} \leq 0.05)$.

KEY WORDS: Cheek biting, stress, anxiety, depression, para function, dental visits.

HOW TO CITE: Baig NN, Abid K, Fatima R, Ahsan SB. The prevalence of stress \& anxiety among patients having habit of cheek biting. J Pak Dent Assoc 2018;27(2):62-66.

DOI: https://doi.org/10.25301/JPDA.272.62

Received: 29 November 2017, Accepted: 22 March 2018

\section{INTRODUCTION}

$\mathrm{M}$ orsicatio buccarum which is also known as cheek biting is a condition characterized by chronic irritation or injury to the buccal mucosa, caused by repetitive chewing, biting or nibbling. ${ }^{1}$ It is a harmless condition for most of the people who accidentally bite their cheeks, but it can become a harmful condition for those who developed a habit of biting of their cheeks.

The common causes of morsicatio buccarum are misalignment of wisdom teeth, temporomandibular joint disorder, jaw closure problem and ill fitting dentures. On the other hand morsicatio buccarum are often observed in

1. Senior Executive Officer Research, Department of Research Evaluation Unit, College of Physicians and Surgeons Pakistan.

2. Senior Biostatistician, Department of Research Evaluation Unit, College of Physicians and Surgeons Pakistan.

3. Dental Surgeon, Department of Dental section, Ameen Medical and Dental Center.

4. Medical Officer, Department of Clinical, Saifee Hospital

Corresponding author: "Khadijah Abid" < khadijahabid@gmail.com > people who are under stress, anxiey or with psychogenic background. ${ }^{2}$ Biting of oral mucosa is seen in 750 per million persons. In a Mexican dental school clinic of 23,785 patients, cheek-biting lesions were found to be fifth most common oral mucosal finding with a prevalence of 21.7 cases per 1000 patients. ${ }^{1}$

The prevalence of cheek biting is more in children and females. ${ }^{1}$ In a study conducted by A. P Vanderas et al. the prevalence of cheek biting was reported as $60.51 \%$; whereas headaches showed statistical significance with cheek biting (P-value $<0.05$ ) among children. ${ }^{3}$ A case report on 10 year old boy with history of biting of cheeks associated with major depressive disorder. ${ }^{1}$ In an another study conducted at Saudi Arab headache was observed as 33\% among the oral parafunctions and cheek biting was the most prevalent $41 \%{ }^{4}$

Anxiety \& stress are potential risk factors for impaired oral health status. ${ }^{5}$ The rationale for initiating this study was scarce data available on this topic although, it is a common 
phenomenon but it never gets the attention of the dentists. The main purpose of this study was to assess the prevalence of stress and anxiety among patients having habit of cheek biting in Pakistani population.

\section{METHODOLOGY}

It was a cross-sectional study conducted at Ameen Medical and Dental Center, Karachi from July 2016 to Jul 2017. After taking approval from hospital MD total of 101 patients were included in the study using non-probability consecutive sampling technique. Sample size of 101 was estimated using Open Epi online sample size calculator by taking statistics for anxiety disorder as $30.6 \%{ }^{6}$ among facial pain disorder \& margin of error as $9 \%$ at $95 \%$ confidence level. All the patients of age 16-65 years of either gender coming to OPD for routine dental check-up with complain of pain and burning in oral cavity were included in the study. Cheek biting was assessed clinically, injury to the buccal mucosa was labelled as positive. Patients with obesity,pregnancy, previous dental treatment specially proctitis or taking pan/gutka and with history of smoking or alcohol intake were excluded from the study.

Inform consent was taken from the participants. Perceived stress scale (PSS) was used to assess stress. The patient with score $>20$ was labeled as stressed. Hamilton Anxiety Rating Scale (HAM-A) was used to assess anxiety. The patient with score $>20$ was labeled as anxiety positive. We used a translated version of questionnaire for patients who cannot understand the language. All information was recorded in a pre-designed proforma by the researcher.

Data was analyzed using STATA version 11.1. Quantitative variables were presented as mean and standard deviation. Qualitative variables were presented as frequency and percentage. Chi-sq test was applied and p-value $\leq 0.05$ was taken as significant.

\section{RESULTS}

Total of 101 participants were enrolled in the study, out of which 58(57.4\%) were females and 43(42.6\%) were males. The mean age was calculated as 34.73 years \pm 12.98

Figure 1: Presence of stress and anxiety in patients with habit of cheek biting

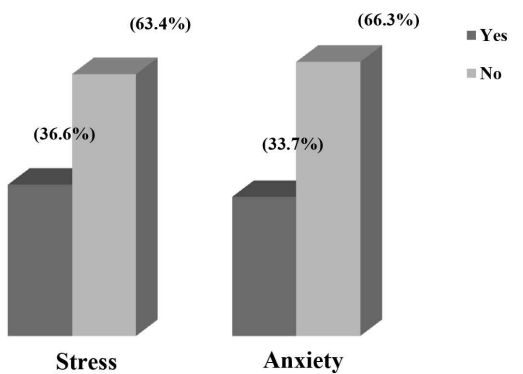

SD. Most of the participants were from adult age group $68.3 \%$. Out of $101,52.5 \%$ were graduate, $17(16.8 \%)$ were from secondary education, $16(15.8 \%)$ were from primary

Table 1: Socio-demographic characteristics of study variables

\begin{tabular}{|c|c|c|}
\hline $\begin{array}{c}\text { Demographic Characteristics } \\
(\mathrm{n}=101)\end{array}$ & $\mathbf{N}$ & $\%$ \\
\hline Age in yrs.(Mean \pm SD) & \multicolumn{2}{|c|}{$34.73 \pm 12.98$} \\
\hline Youngs(15-24yrs) & 29 & 28.7 \\
\hline Adults(25-64yrs) & 69 & 68.3 \\
\hline Seniors(65yr and above) & 3 & 3.0 \\
\hline \multicolumn{3}{|l|}{ Gender } \\
\hline Male & 43 & 42.6 \\
\hline Female & 58 & 57.4 \\
\hline \multicolumn{3}{|l|}{ Educational level } \\
\hline None & 5 & 5.0 \\
\hline Primary & 16 & 15.8 \\
\hline Secondary & 17 & 16.8 \\
\hline Graduate & 53 & 52.5 \\
\hline Post Graduate & 10 & 9.9 \\
\hline \multicolumn{3}{|l|}{ Monthly household income(Rps) } \\
\hline$<15,000$ & 18 & 17.8 \\
\hline $15,000-35,000$ & 61 & 60.4 \\
\hline$>35,000$ & 22 & 21.8 \\
\hline \multicolumn{3}{|l|}{ Marital Status } \\
\hline Single/Never Married & 42 & 41.6 \\
\hline Divorced/widowed/separated & 13 & 12.9 \\
\hline Married & 46 & 45.5 \\
\hline \multicolumn{3}{|l|}{ Job Status } \\
\hline Unemployed & 31 & 30.7 \\
\hline Housewives & 19 & 18.8 \\
\hline Retired & 2 & 2.0 \\
\hline Employed & 49 & 48.5 \\
\hline \multicolumn{3}{|l|}{ Family Status } \\
\hline Joint & 62 & 61.4 \\
\hline Nuclear & 39 & 38.6 \\
\hline \multicolumn{3}{|l|}{ Psychiatric illness in family } \\
\hline Yes & 10 & 9.9 \\
\hline No & 91 & 90.1 \\
\hline \multicolumn{3}{|l|}{ Diabetes in family } \\
\hline Yes & 23 & 22.8 \\
\hline No & 78 & 77.2 \\
\hline \multicolumn{3}{|l|}{ Leisure-time physical activity level } \\
\hline Active & 66 & 65.3 \\
\hline Inactive & 35 & 34.7 \\
\hline
\end{tabular}


education, $10(9.9 \%)$ were post graduate and only $5(5 \%)$ were illiterate. Majority of the patients were from middle income level $60.4 \%, 45.5 \%$ were married, $48.5 \%$ were employed, $61.4 \%$ were from joint family, $90.1 \%$ were without history of psychiatric illness, $77.2 \%$ had family history of DM \& $65.3 \%$ of the participants were physically active. (Table 1)
As depicted in Figure 1, out of 101 participants, stress was observed in only $37(36.6 \%) \&$ anxiety was observed in only $34(33.7 \%)$.

In univariate analysis, stress showed significant difference with psychiatric illness $(p=0.003)$ and with family history of DM ( $p=0.001)$ whereas anxiety was only statistical significant with family history of DM $(\mathrm{p}=0.033)$. (Table 2 )

Table 2: Stratification of effect modifiers for stress and Anxiety

\begin{tabular}{|c|c|c|c|c|c|c|}
\hline \multirow[b]{2}{*}{ Variables } & \multicolumn{2}{|c|}{ Stress } & \multirow[b]{2}{*}{ P-value } & \multicolumn{2}{|c|}{ Anxiety } & \multirow[b]{2}{*}{ P-value } \\
\hline & Yes(n=37) & No(n=64) & & Yes(n=37) & $\operatorname{No}(n=64)$ & \\
\hline \multicolumn{7}{|l|}{ Age Groups } \\
\hline Youngs(15-24 years) & $7(18.9 \%)$ & $22(34.4 \%$ & 0.243 & $10(29.4 \%)$ & $19(28.4 \%)$ & 0.994 \\
\hline ADULTS(25-64 years) & $29(78.4 \%)$ & $40(62.5 \%)$ & & $23(67.6 \%)$ & $46(68.7 \%)$ & \\
\hline Seniors(=>65years) & $1(2.7 \%)$ & $2(3.1 \%)$ & & $1(2.9 \%)$ & $2(3.0 \%)$ & \\
\hline \multicolumn{7}{|l|}{ Gender } \\
\hline Male & $13(35.1 \%)$ & $30(46.9 \%)$ & 0.25 & $12(35.3 \%)$ & $31(46.3 \%)$ & 0.292 \\
\hline Female & $24(64.9 \%)$ & $34(53.1 \%)$ & & $22(64.7 \%)$ & $36(53.7 \%)$ & \\
\hline \multicolumn{7}{|l|}{ Educational level } \\
\hline None & 0 & $5(7.8 \%)$ & 0.429 & $2(5.9 \%)$ & $3(4.5 \%)$ & 0.764 \\
\hline Primary & $7(18.9 \%)$ & $10(15.6 \%)$ & & $5(14.7 \%)$ & $11(16.4 \%)$ & \\
\hline Secondary & $19(51.4 \%)$ & $10(15.6 \%)$ & & $8(23.5 \%)$ & $9(13.4 \%)$ & \\
\hline Graduate & $19(51.4 \%)$ & $34(53.1 \%)$ & & $16(47.1 \%)$ & $37(55.2 \%)$ & \\
\hline Post Graduate & $5(13.5 \%)$ & $5(7.8 \%)$ & & $3(8.8 \%)$ & $7(10.4 \%)$ & \\
\hline \multicolumn{7}{|l|}{ Monthly household income(Rps) } \\
\hline$<15,000$ & $6(16.2 \%)$ & $12(18.8 \%)$ & 0.494 & $8(23.5 \%)$ & $10(14.9 \%)$ & 0.565 \\
\hline $15,000-35,000$ & $25(67.6 \%)$ & $36(56.3 \%)$ & & $19(55.9 \%)$ & $42(62.7 \%)$ & \\
\hline$>35,000$ & $6(16.2 \%)$ & $16(25 \%)$ & & $7(20.6 \%)$ & $15(22.4 \%)$ & \\
\hline \multicolumn{7}{|l|}{ Marital Status } \\
\hline Single/Never married & $14(37.8 \%)$ & $28(43.8 \%)$ & 0.663 & $16(47.1 \%)$ & $26(38.8 \%)$ & 0.729 \\
\hline Divorced/widowed/separated & $4(10.8 \%)$ & $9(14.1 \%)$ & & $4(11.8 \%)$ & $9(13.4 \%)$ & \\
\hline Married & $19(51.4 \%)$ & $27(42.2 \%)$ & & $14(41.2 \%)$ & $32(47.8 \%)$ & \\
\hline \multicolumn{7}{|l|}{ Job Status } \\
\hline Unemployed & $11(29.7 \%)$ & $20(31.3 \%)$ & 0.92 & $13(38.2 \%)$ & $18(26.9 \%)$ & 0.616 \\
\hline Housewives & $8(21.6 \%)$ & $11(17.2 \%)$ & & $6(17.6 \%)$ & $13(19.4 \%)$ & \\
\hline Retired & $1(2.7 \%)$ & $1(1.6 \%)$ & & $1(2.9 \%)$ & $1(1.5 \%)$ & \\
\hline Employed & $17(45.9 \%)$ & $32(50 \%)$ & & $14(41.2 \%)$ & $35(52.2 \%)$ & \\
\hline \multicolumn{7}{|l|}{ Family Status } \\
\hline Joint & $22(59.5 \%)$ & $40(62.5 \%)$ & 0.762 & $18(52.9 \%)$ & $44(65.7 \%)$ & 0.436 \\
\hline Nuclear & $15(40.5 \%)$ & $24(37.5 \%)$ & & $16(47.1 \%)$ & $23(34.3 \%)$ & \\
\hline \multicolumn{7}{|l|}{ Psychiatric illness in family } \\
\hline Yes & $8(21.6 \%)$ & $2(3.1 \%)$ & 0.003 & $4(11.8 \%)$ & $6(9 \%)$ & 0.052 \\
\hline No & $29(78.4 \%)$ & $62(96.9 \%)$ & & $30(88.2 \%)$ & $61(91 \%)$ & \\
\hline \multicolumn{7}{|l|}{ Diabetes in family } \\
\hline Yes & $18(48.6 \%)$ & $5(7.8 \%)$ & 0.001 & $12(35.3 \%)$ & $11(16.4 \%)$ & 0.033 \\
\hline No & $19(51.4 \%)$ & $59(92.2 \%)$ & & $22(64.7 \%)$ & $56(83.6 \%)$ & \\
\hline \multicolumn{7}{|l|}{ Leisure-time physical activity level } \\
\hline Active & $25(67.6 \%)$ & $41(64.1 \%)$ & 0.721 & $26(76.5 \%)$ & $40(59.7 \%)$ & 0.094 \\
\hline Inactive & $12(32.4 \%)$ & $23(35.9 \%)$ & & $8(23.5 \%)$ & $27(40.3 \%)$ & \\
\hline
\end{tabular}




\section{DISCUSSION}

Oral mucosal lesions are a multi factorial disease. Therefore, recognizing the risk factors promoting this condition plays an important role in its management and prevention. It was found that psychological stressors and depression may propagate its progression. ${ }^{7}$ The aim of this study was to determine the frequency of stress and anxiety among patients with habit of cheek biting visiting dental clinic for routine checkups. We found about $36.6 \%$ patients were stressed and anxiety was present in $33.7 \%$ patients. A case report on a 10-year-old boy who presented with multiple ulcerations over lower lip, diagnosed as a case of Major Depressive disorder was treated with anti-depressant and his condition improved. ${ }^{1}$ In another study, depression and anxiety were evaluated, the results showed $82 \%$ of TMD had anxiety and $57 \%$ had depression. In the present study most of the patients were from adults age group among them $78.4 \%$ had stress and $67.6 \%$ had anxiety.

In the present study, majority of the patients were females $57.4 \%$, among them $64.9 \%$ had stress and $64.7 \%$ anxiety. A research conducted on patients with temporomandibular disorders showed similar results i.e. $82 \%$ females were affected. According to the study, this could be due to the fact that women seek medical help early or due to psychological and hormonal factors pertaining to females. ${ }^{5}$ A survey at Polish university gave similar results showing significant number of women presenting with temporomandibular disorders and increased psycho emotional activity and stress. The research concluded that people with emotional burden or easily excitable personalities suffered more from oral para functions. ${ }^{7}$

In the presented study, the ratio of graduated patients with stress \& anxiety related cheek biting was high as compared to secondary, primary, post graduate and uneducated. The percentage of stress related cheek biting among employed, unemployed, house wives was found to be $45.9 \%, 29.7 \%, 21.6 \%$ respectively, the percentage of anxiety related cheek biting among employed, unemployed, house wives was found to be $41.2 \%, 38.2 \% \& 17.6 \%$ respectively. In a similar study $58 \%$ student or unemployed people with TMD identified themselves as stressed. Common stressors could be low income, peer pressure, large number of duties, uncertain future or living away from family in a new environment. They also emphasized the fact students are more exposed to social emotional physical and family problem. ${ }^{7}$

Socioeconomic status may be an influencing factor in this regard i.e. individual with low socioeconomic status $17.8 \%$, middle class $60.4 \%$ \& upper class $21.8 \%$ presented with cheek biting. As majority of the patients were from middle level income they had high stress and anxiety level as $67.6 \%$ and $55.9 \%$. According to this data we can conclude social life of a person may play as a stressor and can lead to oral problems.

With regard to marital status, it is indicated that $45.5 \%$ married patients are more prone to cheek biting while only $41.6 \%$ unmarried were affected, out of which stress was observed in $51.4 \%$ of married and $37.8 \%$ unmarried patients whereas anxiety was prevalent among $47.8 \%$ of married and $38.8 \%$ of unmarried patients. Family system plays an important role in the contribution of stress related cheek biting. In our study majority of patients belong from joint family system $61.4 \%$, out of which is $59.5 \%$ had stress while $52.9 \%$ had anxiety. Other studies states that women who are widowed or married but living separately present more with oral problems as compared to men. ${ }^{8}$

In the present study we have also observed the role of history of psychiatric illness \& diabetes mellitus in family among patients with habit of cheek biting as $9.9 \%$ and $22.8 \%$. Among patients with history of psychiatric illness in family stress was present in $21.6 \%$ and anxiety was present in $11.8 \%$, whereas among patients with history of DM in family stress was observed in $48.6 \%$ and anxiety was observed in $35.5 \%$. In the present study, about $65.3 \%$ participants do physical activity in their leisure hours while $34.7 \%$ were physically in-active. Among physically in-active patients stress was prevalent in $32.4 \%$ and anxiety was prevalent in $23.5 \%$.

Furthermore, perspective studies must be conducted with a large data collected from multiple hospitals, including patients of young age to elderly should be taken into account. Other oral conditions like TMD, oral ulcers, lip biting linked with stress, anxiety and depression can be added along with systemic conditions to draw up guidelines for the therapeutic approach to oral mutilation.

\section{CONCLUSION}

We found stress and anxiety were prevalent among patients with habit of cheek-biting. History of psychiatric illness and diabetes mellitus played significant role and showed statistical relation with stress and anxiety $(\mathrm{p} \leq 0.05)$.

\section{CONFLICT OF INTEREST}

None declared.

\section{REFERENCES}

1. Bhatia NK, Bhatia NK, Bhatia. Morsicatio buccarum and labiorum with depression. Int J Dent Health Sci. 2015; 2(6): 
1639-42.

2. Shamim T. The Psychosomatic Disorders Pertaining to Dental Practice with Revised Working Type Classification. Korean J Pain. 2014; 27(1): 16-22.

https://doi.org/10.3344/kjp.2014.27.1.16

3. Vanderas AP, Papagiannoulis L. Multifactorial analysis of the aetiology of craniomandibular dysfunction in children. Int J Paediat Dent. 2002; 12:336-46. https://doi.org/10.1046/j.1365-263X.2002.00380.x

4. Feteih RM. Signs and symptoms of temporomandibular disorders and oral parafunctions in urban Saudi arabian adolescents: a research report. Head Face 2006; 2(25): $1-7$.

https://doi.org/10.1186/1746-160X-2-25

5. Beitollahi JM, Mansourian A, Bozorgi Y, Farrokhnia T, Manavi A. Evaluating the most common etiologic factors in patients with TMDs: a case control study. J. Applied Sci. 2008; 8(24): 4702-5.

https://doi.org/10.3923/jas.2008.4702.4705

6. Mongini F. Temporomandibular disorders and tensiontype headache. Current pain and headache reports. 2007 Dec 1;11(6):465-70. https://doi.org/10.1007/s11916-007-0235-z

7. Wieckiewicz M, Grychowska N, Wojciechowski K, Pelc A, Augustyniak M, Sleboda A et al. Prevalence and Correlation between TMD Based on RDC/TMD Diagnoses, Oral Parafunctions and Psychoemotional Stress in Polish University Students ; Biomed Res Int. 2014; 2014:1-6. 8. Mundt T, Mack F, Schwahn C, Bernhardt O, Kocher T, Biffar R. Association between sociodemographic, behavioral and medical conditions and signs of temporomandibular disorders across gender: Results of the study of health in Pomerania (SHIP-0). Int J Prosthdont. 2008; 21(2): 141-8. 9. Roda RP, Bagan JV, Sanchis JM, Carbonell E.
Temporomandibular disorders. a case-control study. Med Oral Patol Oral Cir Bucal. 2012; 17(5): 794-800. https://doi.org/10.4317/medoral.18040

10. Aljameel AH, Watt RG, Brunner EJ, Tsakos G. Earlier depression and later-life self-reported chewing dif?culties: results from the Whitehall II study. J Oral Rehabil. 2014; 42: 98-104.

https://doi.org/10.1111/joor.12232

11. Liao CH, Chang CS, Chang SN, Lyu SY, Morisky DE, Sung FC. The risk of temporomandibular disorder in patients with depression: a population-based cohort study. Community Dent Oral Epidemiol. 2011; 39:525-31.

https://doi.org/10.1111/j.1600-0528.2011.00621.x 12. Beandini DA, Benson J, Nicholas MK, Murray GM, Peck CC. Chewing in temporomandibular disorder patients: an exploratory study of an association with some psychological variables. J Orofac Pain. 2011;25:56-67. 13. Winocur E, Gavish A, Finkelshtein T, Halachmi M, Gazit E. Oral habits among adolescent girls and their association with symptoms of temporomandibular disorders. J Oral Rehabil. 2001;28: 624-9. https://doi.org/10.1046/j.1365-2842.2001.00708.x 14. Rai B, Kaur J, Anand SC, Jacobs R. Salivary stress markers, stress, and periodontitis: a pilot study. J Periodontol 2011; 82: 287-92. https://doi.org/10.1902/jop.2010.100319

15. Peruzzo DC, Benatti BB, Ambrosano GM, NogueiraFilho GR, Sallum EA, Casati MZ, et al. A systematic review of stress and psychological factors as possible risk factors for periodontal disease. J Periodontol 2007; 78: 1491-504. https://doi.org/10.1902/jop.2007.060371

16. Egermark EI. Mandibular dysfunction in children and in individuals with dual bite. Swedish Dent J 1982; 10: 145. 